\title{
Diagnóstico situacional de la comunidad Capirona, parroquia Puerto Napo, cantón Tena, provincia de Napo, previo a la elaboración del inventario de atractivos turísticos
}

\author{
Situational analysis of Capirona community, Puerto Napo parish, Tena canton, \\ Napo province, prior to preparation the of inventory of tourist attractions
}

Shakira Lissett Salazar Mora. ${ }^{1}$, Nancy Patricia Tierra Tierra. ${ }^{2}$ \& Edison Marcelo Salas Castelo. ${ }^{3}$

\section{Recibido: 24-04-2020 / Revisado: 15-05-2020 / Aceptado: 25-06-2020 / Publicado: 03-07-2020}

\begin{abstract}
.
DOI: https://doi.org/10.33262/cienciadigital.v4i3.1360

The situational analysis is the starting point for the preparation of plans and programs aimed at the sustainable development of a territory regardless of its location. As a planning tool, situation analyses are used in various disciplines for planning the development of localities and communities. In the same way, in tourism, as a strategy for sustainable territorial development, the situational analysis allows us to have a clear vision of the current environment in which intervention is needed. This article presents the situational analysis developed in Capirona community, Puerto Napo parish, Tena canton, Napo province. The situational analysis was prepared as part of the Inventory of Tourist Attractions of the community. For the development of the diagnosis, the SEMPLADES 2015 methodology was used, which allowed knowing the capacities, needs, and precarious conditions in which Capirona community inhabitants live. Among the main problems, the lack of basic services such as drinking water service, sewer system, solid waste collection and electrical system, were detected. Also, the poor state of the access roads, unemployment, migration, poaching and destruction of forests by cutting down trees are pressing issues. It is important to highlight that the main form of subsistence of the community's inhabitants is agriculture; $80 \%$ for own consumption and $20 \%$ for commercialization. In this context, the development of other productive activities, such as sustainable tourism, can potentially help generate necessary resources for the inhabitants of Capirona community. Finally, the situational analysis shows the need for attention from the authorities to assist the residents to get out of the economic, social and environmental stagnation in which they are now.
\end{abstract}

Keywords: Puerto Napo, sustainable tourism, rural tourism, biodiversity, sustainable development

\footnotetext{
${ }^{1}$ Investigadora Independiente, Chimborazo Ecuador, lissettsalazar1995@gmail.com

${ }^{2}$ Escuela Superior Politécnica de Chimborazo - Facultad de Recursos Naturales, ntierra@espoch.edu.ec

${ }^{3}$ Escuela Superior Politécnica de Chimborazo - Facultad de Recursos Naturales. Secretaría Nacional de Ciencia, Tecnología e Innovación SENESCYT - Ecuador, esalas@espoch.edu.ec
} 


\section{Resumen}

La elaboración del diagnóstico situacional es el punto de partida para la elaboración de planes y programas tendientes al desarrollo sostenible de un territorio, sin importar donde este se encuentre. Como herramienta de planificación, el diagnóstico situacional se emplea en diversas disciplinas y, como en este caso, para el desarrollo de localidades y comunidades. De la misma forma, en el turismo, como estrategia de desarrollo territorial sostenible, el diagnóstico situacional nos permite tener una visión clara del entorno actual en el cual queremos intervenir. El presente artículo presenta el diagnóstico situacional desarrollado en la comunidad Capirona en la parroquia de Puerto Napo, cantón Tena, provincia de Napo, mismo que se elaboró como parte del Inventario de Atractivos Turísticos de la comunidad. Para el desarrollo del diagnóstico se empleó la Metodología SEMPLADES 2015, el cual permitió conocer las potencialidades, necesidades y precarias condiciones en que viven sus pobladores. Entre los principales problemas resaltan la inexistencia de servicios básicos tales como; agua potable, sistema eléctrico, sistema de alcantarillado, recolección de residuos sólidos entre otros. A estos problemas se suman el mal estado de las vías de acceso, desempleo, migración, cacería furtiva y destrucción de bosques por la tala de árboles. Es importante resaltar que la forma principal de subsistencia de los pobladores de la comunidad es la agricultura; $80 \%$ para consumo propio y un $20 \%$ para comercialización. En este contexto, el desarrollo de otras actividades, como el turismo sostenible, pueden, potencialmente, ayudar a generar recursos necesarios para los habitantes de la comunidad Capirona. Finalmente, el diagnóstico situacional pone de manifiesto la necesidad de atención por parte de las autoridades que permita a los pobladores salir del estancamiento económico, social y ambiental en el cual se encuentran al momento.

Palabras clave: Puerto Napo, turismo sustentable, turismo rural, biodiversidad, desarrollo sustentable

\section{Introducción.}

De acuerdo con la Organización Mundial del Turismo [OMT] (2020), el turismo es aquel fenómeno social, cultural y económico que involucra el desplazamiento de personas fuera de su lugar de residencia habitual por diferentes motivos, los cuales pueden ser personales, profesionales o de negocios. Además, dicho desplazamiento de personas es de carácter temporal y por un relativamente corto periodo de tiempo (OMT, 2020). La actividad turística se ha convertido en una de las principales fuentes de ingresos económicos para distintos países del mundo. La contribución del turismo a la economía mundial, en el año 2019, se situó en el 10,4\% del PIB global (World Travel and Tourism Council [WTTC], 2020). El turismo durante los años ha experimentado un crecimiento continuo y diversificado hasta convertirse en uno de los sectores económicos que crece con mayor rapidez en el mundo (OMT, 2019; WTTC, 2020). El turismo posee una estrecha relación con el desarrollo y mejoramiento de las condiciones de vida de las personas del territorio en el cual se realiza. Sin embargo, el turismo puede no ser compatible con los objetivos de la sostenibilidad, ya que muchas veces se enfoca al turismo solo desde la perspectiva del crecimiento económico (HigginsDesbiolles, 2018). Consecuentemente, la preocupación por lograr un turismo sostenible ha animado crecientemente a buscar modalidades y productos turísticos que encajen y respeten las culturas y el medio ambiente (Linares \& Garrido, 2014). 
En este contexto, Ecuador al contar en su territorio con pueblos milenarios que han conservado sus costumbres y tradiciones, ha visto en el turismo una oportunidad para que cada una de estas nacionalidades y pueblos compartan con el mundo sus tradiciones, sus costumbres, formas de vida y el entorno natural maravilloso en que habitan inculcando a la vez, el respeto y amor por la Pachamama, enfatizando la diversidad de identidades existentes y haciendo del episodio turístico una experiencia más plena y profunda. Por lo tanto, el desarrollo turístico de los territorios se debe alcanzar desde una perspectiva de sostenibilidad, potenciando el desarrollo de actividades turísticas responsables que tengan como objetivo la conservación de los recursos naturales y culturales, que además permitan el bienestar local por medio del aseguramiento de una viabilidad económica y la sensibilización a los visitantes y gestores turísticos, a través de la educación e interpretación ambiental (Ministerio del Ambiente, 2020). Es decir, potenciando los aspectos sociales, ambientales y económicos de las zonas donde se planifica la intervención turística.

El cantón Tena es uno de los cantones más reconocidos de la Amazonia Ecuatoriana por albergar en su territorio una gran biodiversidad, así como una infinidad de atractivos turísticos tanto naturales como culturales, los cuales están complementados con una amplia infraestructura y planta turística. Dentro del cantón Tena se asientan 7 parroquias rurales, en las cuales, a su vez, se encuentran varias comunidades indígenas amazónicas (Gobierno Autónomo Descentralizado Municipal de Tena, 2014). Lo cual hace necesario implementar estrategias que permitan que los distintos territorios y sus comunidades se conviertan en auténticos elementos distintivos dentro de la actividad turística sostenible que a su vez se vinculen y generen una relación beneficiosa que permita dinamizar la economía en el territorio.

Por este motivo, el Gobierno Autónomo Descentralizado Parroquial Rural de Puerto Napo considerando al turismo como una de sus actividades productivas propuso la realización del diagnóstico situacional de varias de las comunidades que se encuentran bajo su jurisdicción, como es el caso de la Comunidad Capirona, para que sirva como insumo para la posterior evaluación del potencial turístico de la comunidad.

\section{Diagnóstico situacional}

Previo a la realización de cualquier intervención en territorio, es necesario conocer la realidad actual del mismo para que las estrategias, políticas y acciones a implementarse conlleven mejoras y así, optimizar los recursos existentes e impactar positiva y efectivamente sobre los elementos del territorio que requieran mayor atención (Pineda Nariño \& Arias Guarín, 2014).

El estudio de esa realidad del territorio se conoce como diagnóstico situacional, el cual es el procedimiento técnico, planificado y sistemático que permite identificar describir y evaluar la situación de una empresa, territorio, comunidad, etc. en un momento específico. Así, los resultados del diagnóstico situacional servirán también como marco de referencia para comparar la situación del territorio antes y después de cualquier intervención implementada, permitiendo a su vez realizar correcciones o ampliaciones a las actividades en principio planificadas. En este contexto, Hernandez (2015) expresa que el diagnostico situacional se refiere a la identificación, descripción y análisis evaluativo de la situación actual de la organización o de un territorio.

\section{Metodología.}

El presente estudio se realizó en la comunidad Capirona, parroquia Puerto Napo, cantón Tena, Provincia de Napo. El trabajo de campo se realizó en el mes de agosto de 2019 durante 20 días. Para la recolección de datos se realizó talleres participativos y, en algunos casos, entrevistas personalizadas en la casa de los 
participantes que no pudieron asistir a los talleres. También es necesario indicar que previo a la recolección de datos se realizaron reuniones de acercamiento con los integrantes de la comunidad y de planificación con los líderes comunitarios y las autoridades de la parroquia Puerto Napo a la cual la comunidad Capirona pertenece.

El diagnóstico situacional de la comunidad Capirona se realizó siguiendo los lineamientos de la metodología de la Secretaría Nacional de Planificación y Desarrollo [SENPLADES] (2015). La SENPLADES, en la actualidad es la Secretaría Técnica Planifica Ecuador. Según la metodología SENPLADES, el diagnóstico situacional se realiza mediante el levantamiento de información en campo, para lo cual se emplean diferentes instrumentos: boletas censales, fichas ambientales, fichas etnobotánicas y fichas etnozoológicas, las cuales permiten registrar información ambiental, así como, información organizativa y cultural.

\section{Metodología SENPLADES}

La metodología SENPLADES para la elaboración de planes de desarrollo y ordenamiento territorial está conformada por varios ámbitos, los cuales a su vez están compuestos de siete subámbitos, mismos que se detallan en la Tabla 1.

Tabla 1. Metodología SEMPLADES para la Elaboración de Planes de Desarrollo y Ordenamiento Territorial

\begin{tabular}{|c|c|c|}
\hline & \multicolumn{2}{|c|}{ Subámbitos } \\
\hline Biofísico & $\begin{array}{l}\text { - Uso y cobertura del suelo. } \\
\text { - Recursos naturales renovables y no } \\
\text { renovables con valor económico, energético, } \\
\text { ambiental. } \\
\text { - Recursos naturales degradados y sus causas. } \\
\text { - Impactos y niveles de contaminación. } \\
\text { - Ecosistemas frágiles y prioridades de } \\
\text { conservación. }\end{array}$ & 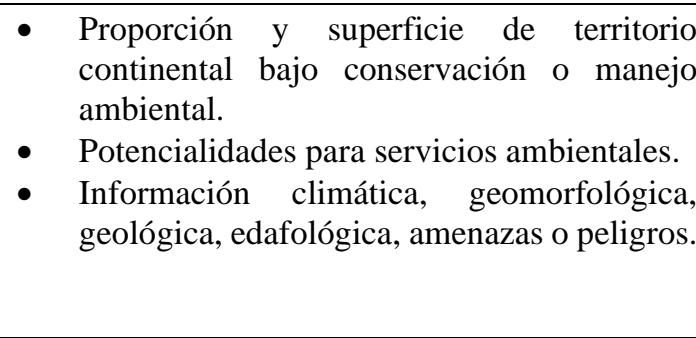 \\
\hline Sociocultural & $\begin{array}{l}\text { - Análisis demográfico: población total, tasa } \\
\text { de crecimiento poblacional inter-censal, } \\
\text { proyecciones demográficas; distribución de } \\
\text { la población por edad y sexo, distribución de } \\
\text { la población por área de residencia; auto } \\
\text { identificación étnica de la población. } \\
\text { Educación: Tasa de asistencia por nivel de } \\
\text { educación; escolaridad de la población, } \\
\text { analfabetismo y deserción escolar. } \\
\text { Cohesión social y pertenencia de la } \\
\text { población con un territorio. }\end{array}$ & 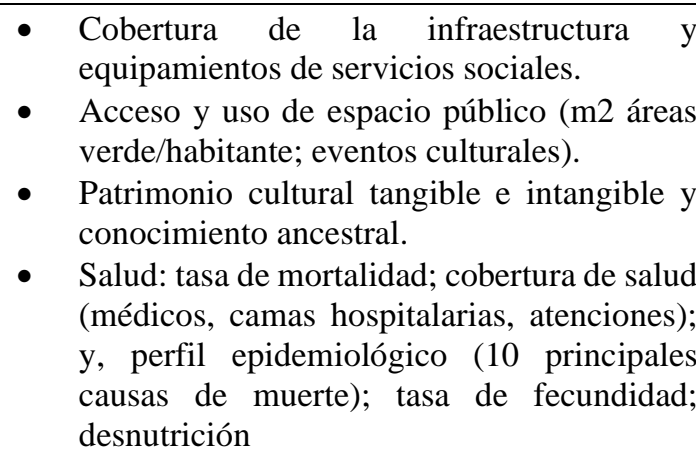 \\
\hline Económico & $\begin{array}{l}\text { - Estructura productiva: Valor Agregado } \\
\text { Bruto (VAB) por rama de actividad } \\
\text { económica. } \\
\text { - } \\
\text { - } \\
\text { Pelación entre sectores económicos. } \\
\text { territorio. } \\
\text { - Factores productivos. }\end{array}$ & $\begin{array}{l}\text { Principales productos: volumen de producción y } \\
\text { productividad. } \\
\text { Número de establecimientos: manufactura y } \\
\text { artesanía, comercio, servicios. } \\
\text { Sistema financiero, recaudación de impuestos } \\
\text { SRI y GAD. }\end{array}$ \\
\hline
\end{tabular}




\begin{tabular}{|c|c|c|}
\hline $\begin{array}{l}\text { Asentamiento } \\
\text { s Humanos }\end{array}$ & $\begin{array}{l}\text { - Red nacional de asentamientos humanos. } \\
\text { - Infraestructura y acceso a servicios } \\
\text { básicos, déficit, cobertura. } \\
\text { - Acceso de la población a servicios de } \\
\text { educación y salud. }\end{array}$ & $\begin{array}{l}\text { - Acceso de la población a vivienda. } \\
\text { - Localización y descripción de los asentamientos } \\
\text { humanos. } \\
\text { - } \begin{array}{l}\text { Dispersión, concentración poblacional y de } \\
\text { servicios sociales y públicos. }\end{array}\end{array}$ \\
\hline $\begin{array}{l}\text { lad, } \\
\text { y } \\
\text { vidad }\end{array}$ & $\begin{array}{l}\text { - } \begin{array}{l}\text { Acceso a servicios de } \\
\text { telecomunicaciones. }\end{array} \\
\text { - } \begin{array}{l}\text { Potencia instalada y tipo de generación de } \\
\text { energía eléctrica. }\end{array} \\
\text { - } \begin{array}{l}\text { Presencia de proyectos estratégicos } \\
\text { nacionales y el recurso natural asociado. }\end{array}\end{array}$ & $\begin{array}{l}\text { - Infraestructura de apoyo a la producción } \\
\text { existente en el territorio. } \\
\text { Estructura, disponibilidad, localización y } \\
\text { jerarquía referida a infraestructura de movilidad } \\
\text { y logística (terrestre, aérea, marina, fluvial). } \\
\text { Identificar los principales problemas y } \\
\text { potencialidades. }\end{array}$ \\
\hline $\begin{array}{l}\text { Político } \\
\text { institucional } \\
\text { y } \\
\text { participación } \\
\text { ciudadana }\end{array}$ & $\begin{array}{l}\text { - Instrumentos de planificación y } \\
\text { ordenamiento territorial vigentes o } \\
\text { existentes en el GAD, así como el marco } \\
\text { legal vigente. } \\
\text { Estructura y capacidades del gobierno } \\
\text { autónomo descentralizado para la gestión } \\
\text { del territorio, incluye análisis del talento } \\
\text { humano. }\end{array}$ & $\begin{array}{l}\text { - Análisis y sistematización de experiencias sobre } \\
\text { planificación y ordenamiento territorial en el } \\
\text { gobierno autónomo descentralizado. } \\
\text { - Análisis y sistematización de experiencias en } \\
\text { participación ciudadana. } \\
\text { - Mapeo de actores públicos, privados, sociedad } \\
\text { civil. }\end{array}$ \\
\hline
\end{tabular}

Fuente: Secretaría Nacional de Planificación y Desarrollo (2015)

\section{Resultados}

\section{Diagnóstico situacional por ámbitos y subámbitos de la comunidad de capirona}

\section{a. Biofísico}

El presente diagnóstico tiene como objetivo identificar y caracterizar el medio biofísico de la comunidad Capirona, parroquia Puerto Napo, así como determinar las interrelaciones de éste con los otros sistemas a ser analizados.

Para el diagnóstico de este componente se han analizado las variables que se presentan a continuación:

\section{Recurso suelo}

Sus principales características son:

Relieve: Según el Gobierno Autónomo Descentralizado Parroquial Rural de Puerto Napo en su Plan de Desarrollo y Ordenamiento Territorial 2015-2019 en esta variable describe las características del relieve asociando a la cobertura y uso de suelo en función de la información del plan cantonal del Gobierno Autónomo Descentralizado Municipal de Tena (GADM Tena). La Parroquia Rural de Puerto Napo, está ubicada al suroriente de la Provincia de Napo, en el cantón Tena, a 194 Km de la capital de Ecuador, Quito (Gobierno Parroquial Rural de Puerto Napo, 2015).

Uso y cobertura del suelo: el conocimiento de la cobertura y uso de la tierra se define como uno de los elementos coyunturales en el análisis biofísico que llevará al adecuado proceso de ordenamiento territorial. El uso no se caracteriza solo por las unidades de paisaje, sino también, 
por su influencia en la formación y evolución de los suelos. La cobertura se refiere a todo lo que ocupa un espacio específico dentro de un ecosistema. Es importante conocer este elemento puesto que ayuda a definir, determinar y cartografiar unidades ecológicas homogéneas. Existen diferentes tipologías de cobertura del suelo, estas se agrupan en clases de acuerdo con sus características, y estas a su vez, se agrupan en unidades que en su orden jerárquico son: vegetal, degradada, hídrica y construida (Gobierno Parroquial Rural de Puerto Napo, 2015).

Cobertura vegetal: la vegetación cumple con las funciones de captación y almacenamiento de energía; refugio de fauna; agente anti-erosivo del suelo; regulador del clima local; reductor de la contaminación atmosférica y del ruido; fuente de materia prima. Se ha revisado una amplia bibliografía respecto a uso y manejo del suelo en la amazonia ecuatoriana, lastimosamente, la información obtenida no muestra datos específicos para la Parroquia de Puerto Napo, más se obtiene caracterización general sobre el sector (Gobierno Parroquial Rural de Puerto Napo, 2015).

Uso actual del suelo: está clasificado como "pasto cultivado más bosque natural". El estudio constató que el suelo no solo es usado para el cultivo de pasto conjugando con manchones de bosque natural secundario, sino también para cultivos menores tales como yuca, maíz, chonta, naranjilla y otros de ciclo corto. Existe también como "pasto cultivo" y para cultivos menores tales como yuca, maíz, y otros de ciclo corto (Gobierno Parroquial Rural de Puerto Napo, 2015).

\section{Recurso agua}

La hidrografía es numerosa y entre sus ríos formadores se encuentran: Napo, Jatunyacu, Ansú, Ilocullín, Pano, Pibi, Ila, Talag, Achiyacu, Mulatos, Verdeyacu, Chucapi, Sinde, Huaysayacu, Moracay, entre otros (Instituto Geográfico Militar, 2020). "En la parroquia se tiene un total de 8 ríos (5 contaminados 62,5\%), 4 riachuelos y 29 vertientes (11 contaminados 37,9\%). En términos generales, el $61 \%$ de los cuerpos de agua están limpios, sin ninguna contaminación aparente" (Gobierno Parroquial Rural de Puerto Napo, 2011).

La principal causa de contaminación es la explotación minería ilegal que desecha las aguas que utiliza sin ningún tipo de tratamiento y las descargas de desechos sólidos de forma directa a los ríos y riachuelos cercanos a su lugar de explotación. La contaminación generada por centros poblados y las descargas de excretas de forma directa a los ríos contribuye a la contaminación de ríos y riachuelos de la parroquia (Gobierno Parroquial Rural de Puerto Napo, 2015).

Después de realizado el levantamiento de información primaria en el sector, se logró determinar que la principal fuente de abastecimiento del líquido vital es el río Puní, mismo que los pobladores han aprovechado para su beneficio y así satisfacer sus necesidades de consumo.

No se recomienda su consumo directo puesto que podría causar afecciones en la salud, ya que está agua no ha pasado por un proceso adecuado de purificación. Así, la calidad de agua que podemos encontrar en la comunidad es muy mala, debido a factores como la contaminación por parte del ser humano. 


\section{Recurso aire}

La calidad del aire en la comunidad es muy buena debido a la poca intervención por parte del ser humano.

\section{Recurso faunístico}

Entre las principales especies de fauna que posee la comunidad de kichwa de Capirona están los insectos tales como grillos, saltamontes, insectos palo, hormigas negras, coloradas, termitas, congas entre otras, anfibios tales como tulumbas, mamíferos tales como osos perezosos, raposas, puercos sajinos, en cuanto a reptiles y aves posee una innumerable cantidad de especies que pueden ser observadas en las cercanías de los ríos y en la parte del bosque primario.

De la fauna identificada en los territorios de la comunidad, las aves y los mamíferos presentaron el mayor número de especies con 25 y 20 especies respectivamente. Los anfibios con 5 especies y crustáceos 3 fueron los grupos con menor número de especies (Tabla 2).

Tabla 2. Recurso faunístico de la comunidad Capirona

\begin{tabular}{lcc}
\hline & FAMILIAS & ESPECIES \\
\hline Reptiles & 10 & 15 \\
\hline Aves & 8 & 25 \\
\hline Mamíferos & 14 & 20 \\
\hline Anfibios & 3 & 5 \\
\hline Peces & 6 & 7 \\
\hline Crustáceos & 3 & 3 \\
\hline TOTAL & $\mathbf{4 4}$ & $\mathbf{7 5}$
\end{tabular}

Fuente: Elaboraciónpropia

Desafortunadamente, muchas de estas especies de fauna se encuentran amenazadas por la pérdida de ecosistemas, la caza furtiva, el tráfico de especies e incluso debido al consumo en exceso por parte de los pobladores de la zona. A eso se suma la amenaza que trae consigo la crisis climática global, aunque los efectos de esta sobre la fauna y flora de la región todavía carecen de suficientes estudios científicos.

\section{Recursos florísticos}

Entre los principales recursos florísticos de la comunidad de Capirona tenemos una extensa variedad de plantas maderables, herbáceas y arbustivas, entre las cuales destacan los árboles de Capirona, sangre de drago, sangre de gallina, caoba, pitón, guabos, caña guadua, ortigas, yuca, cacao, bijao, palmito, chonta, guayusa, ayahuasca, unguragua entre otras especies nativas de la región amazónica y otras introducidas, ya adaptadas hace mucho tiempo a las condiciones del sector. En total, en la comunidad se registró 125 especies pertenecientes a 49 familias. 
De las especies identificadas, una gran cantidad de ellas, 42 son usadas como alimento por los pobladores, mientras que el segundo grupo más grande que comprende 31 especies de plantas son empleadas como medicina y el tercer grupo de que comprende 28 especies son utilizadas tanto como alimento o medicina. También existen 13 especies maderables (Figura 1).

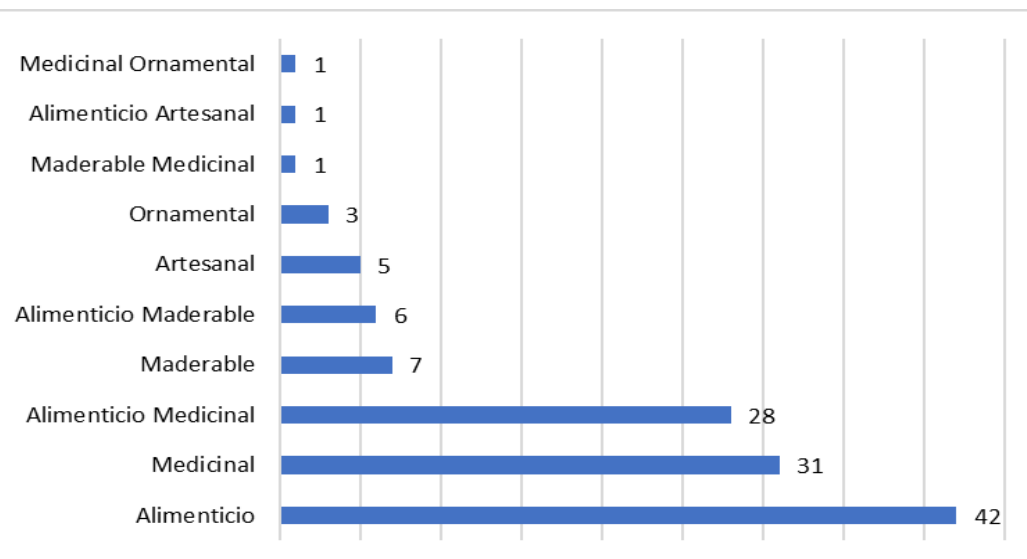

Figura 1. Recursos florísticos de la comunidad, sus principales usos Fuente: Elaboración propia

\section{Amenazas naturales}

Inundaciones: La principal amenaza para la comunidad de Capirona son las inundaciones. Cuando crece el río Puní que la atraviesa, esto limita a los pobladores ya que no pueden lavar la ropa, bañarse y tienen dificultad para acceder al líquido vital, también afecta al transporte fluvial para ir de un lado de la comunidad al otro y para sus chacras.

\section{Resultado general del subsistema biofísico}

La Tabla 3 presenta el resultado general del análisis del subsistema biofísico del territorio dentro perteneciente a la comunidad.

Tabla 3. Síntesis del subsistema biofísico

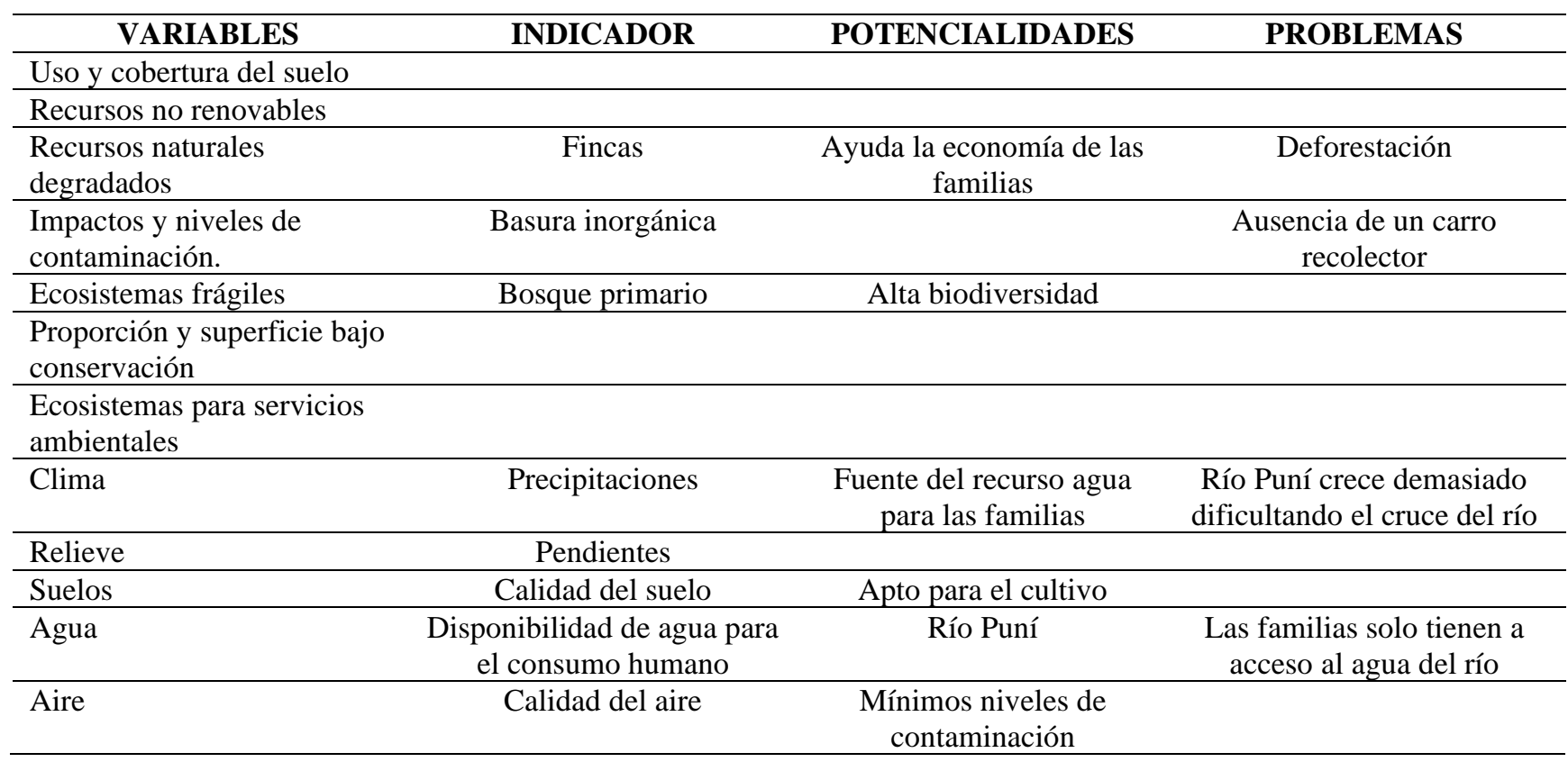

Fuente: Elaboración propia 


\section{b. Sociocultural}

\section{Demografía}

A partir de la información obtenida mediante la Boleta Censal la comunidad Capirona, alberga 334 habitantes, el $49 \%$ corresponde a hombres y el $51 \%$ corresponde a las mujeres, lo que indica que la diferencia de género no es significativa. De acuerdo con los datos obtenidos en los determinados rangos de edad podemos identificar que el porcentaje en niños y niñas representa el $40 \%$, el $17 \%$ a los adolescentes, el $37 \%$ a los adultos y el $6 \%$ corresponde a los adultos mayores.

\section{Estructura familiar}

En la comunidad de Capirona la estructura familiar está conformada por un jefe de familia, que por lo general es el padre, también por su esposa y sus hijos, cabe señalar que en muchas de las viviendas viven de 3 a 4 familias. En cuanto a la educación, 119 niños/as y 49 jóvenes de niños se encuentran estudiando, en dos escuelas existentes en la comunidad de Capirona. Sin embargo, solo 3 jóvenes han completado el bachillerato y 6 la universidad, esto debido a limitantes económicas para acceder a una educación superior.

Las tradiciones y el aprendizaje medicinal se van desvaneciendo en la memoria de las personas con mayor edad y experiencia, lo que obliga a que el $94.37 \%$ de los pobladores del sector se acerquen a un centro de salud para tener una atención especializada. Debido a las limitadas facilidades para una mejor condición de vida y las condiciones climáticas de la zona, las principales enfermedades en su mayoría son afecciones a las vías respiratorias.

\section{Fuente de ingresos familiares}

Las principales actividades económicas de los pobladores, en su gran mayoría son consideradas autónomas, y el restante; depende de la remuneración del estado. Respecto al ingreso económico mensual de los pobladores de la Comunidad Capirona se determinó que: de 71 familias en total, el $94.37 \%$ tiene un ingreso de \$001-\$150. La agricultura es su principal fuente de ingreso, La mayoría de los habitantes poseen terrenos donde cultivan productos para su consumo y

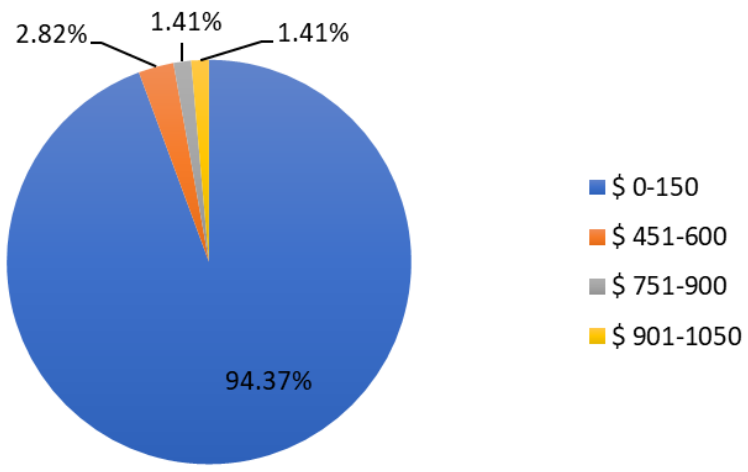

Figura 2. Ingreso mensual promedio por familia Fuente: Elaboración propia para la venta.

El plátano, yuca, maíz, cacao y maní son sus principales productos de cultivo. También se observa que el rango de $\$ 0$-\$50 predomina en cuanto a ingresos mensuales por familia con un $94,37 \%$, lo 
cual demuestra que una familia en esta comunidad vive con un monto muy por debajo, del idóneo para cubrir una canasta básica que garantice el bienestar de cada miembro del hogar (Figura 2).

\section{Migración}

En la búsqueda de mejorar la calidad de vida son 39 los pobladores de la Comunidad Capirona los que han salido a las distintas provincias del país e incluso 1 al extranjero (Figura 3).

En la Figura 4 se puede apreciar que los motivos de la migración de los habitantes de la comunidad Capirona dentro y fuera del país son de tipo socioeconómico y conyugal.

Figura 3. Migración

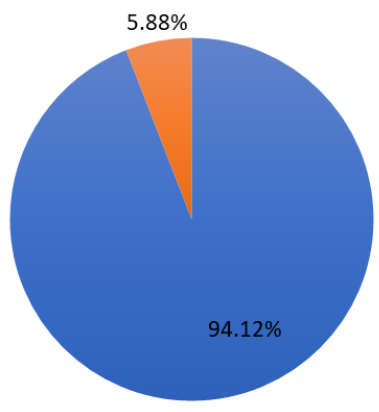

- Dentro del país - Fuera del país

Fuente: Elaboración propia
Figura 4. Motivo de migración

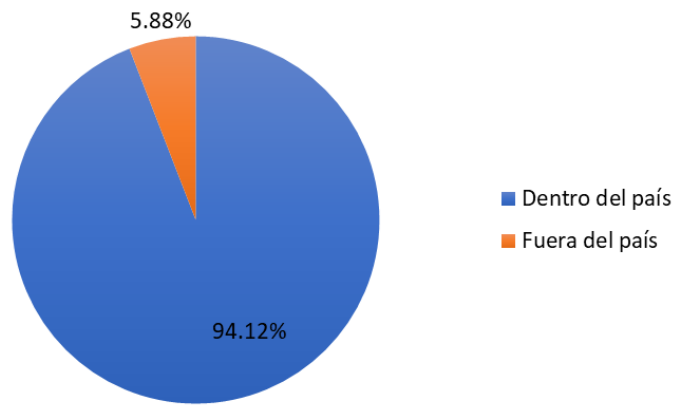

Fuente: Elaboración propia

\section{Organización y tejidos sociales}

La Figura 5 presenta la información con respecto a tejidos sociales: el 36,62\% de la población pertenece a la organización campesina de la comunidad Capirona, el $26,76 \%$ a la organización de mujeres PLATANERAS, el $2,84 \%$ a la Federación de Organizaciones Indígenas del Napo (FOIN)Y EL 1,82\% restante a la Confederación de Nacionalidades Indígenas del Ecuador (CONAIE).

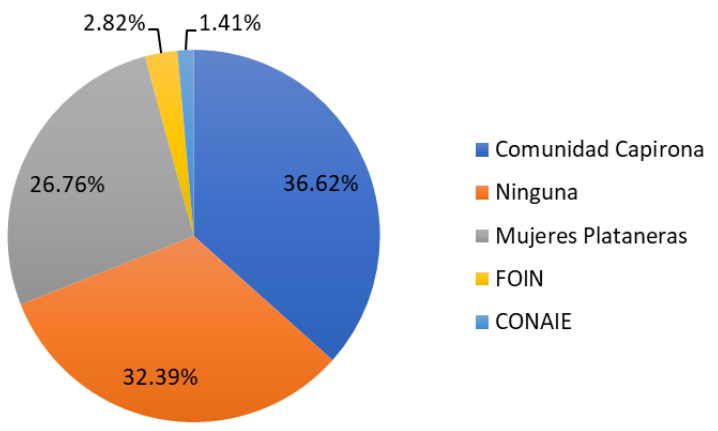

Figura 5. Organizaciones y tejidos sociales Fuente: Elaboración propia 


\section{Composición étnica}

Una vez obtenida la información del sector, podemos ver que la población en su mayoría $(95.77 \%)$ está compuesta por indígenas, seguidos de un 4,23 de población mestiza (Figura 6).

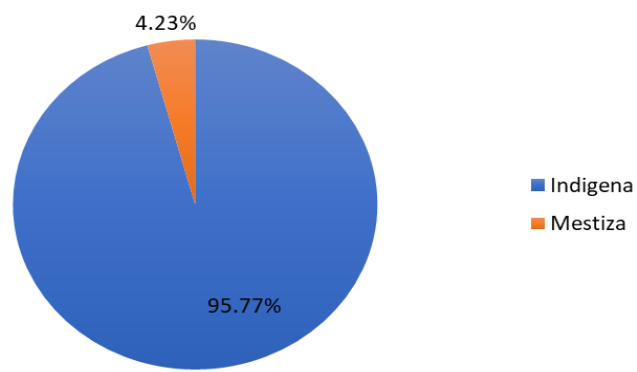

Figura 6. Etnia o nacionalidad

Fuente: Elaboración propia

\section{Patrimonio cultural intangible}

La gran mayoría de los habitantes de la comunidad Capirona se identifican como indígenas Kichwa y habitan en el sector hace muchos años. El patrimonio cultural intangible es variado y aún se conserva algunas tradiciones y costumbres, mientras que otras solo existen en la memoria de algunas personas de la comunidad (Tabla 4).

Tabla 4. Patrimonio cultural intangible

\begin{tabular}{|c|c|c|c|}
\hline $\mathbf{N}$ & Denominación & Sub ámbito & Detalles del Sub ámbito \\
\hline \multicolumn{4}{|c|}{ Ámbito 1 Tradiciones y expresiones orales } \\
\hline \multicolumn{4}{|c|}{0} \\
\hline \multicolumn{4}{|c|}{ Ámbito 2 Artes del espectáculo } \\
\hline 1 & Baile del Tambor & Danza & \\
\hline \multicolumn{4}{|c|}{ Ámbito 3 Usos sociales, rituales y actos festivos } \\
\hline 2 & Ritual Guayusaupina & Rito & Rito apotropaico \\
\hline \multicolumn{4}{|c|}{ Ámbito 4 Conocimientos y usos relacionados con la naturaleza y el universo } \\
\hline 3 & Maito de Sapo & Gastronomía cotidiana & \\
\hline 4 & Maito de Chontacuro & Gastronomía cotidiana & \\
\hline 5 & Maito de Carachama & Gastronomía cotidiana & \\
\hline \multicolumn{4}{|c|}{ Ámbito 5 Técnicas artesanales tradicionales } \\
\hline 6 & Elaboración de Shigras & Tejido con fibras sintéticas & \\
\hline 7 & Elaboración de Atarraya & Tejido con fibras sintéticas & \\
\hline 8 & Elaboración de Ashangas & Tejido con fibras naturales & \\
\hline 9 & Elaboración de Tasas & Tejido con fibras naturales & \\
\hline 10 & Elaboración de Bisutería de Semillas & Artesanías en semillas & \\
\hline 11 & Elaboración de Bisutería de Mullos & Artesanías en mullos & \\
\hline 12 & Elaboración de Pilches & Artesanía en semillas & \\
\hline 13 & Elaboración de la Wami Yasa & Tejido con fibras naturales & \\
\hline 14 & Elaboración de Vasijas de Barro & Alfarería & \\
\hline
\end{tabular}

Fuente: Elaboración propia 


\section{Resultado general del subsistema socio - cultural}

Tabla 5. Síntesis del subsistema socio - cultural por variables principales

\begin{tabular}{|c|c|c|c|}
\hline VARIABLES & INDICADOR & POTENCIALIDADES & PROBLEMAS \\
\hline Demografía & $\begin{array}{l}334 \text { de habitantes, } 169 \\
\text { mujeres y } 165 \text { hombres }\end{array}$ & & \\
\hline Educación & $\begin{array}{c}\text {-CECIB Capirona } \\
\text {-CECIB } 3 \text { de noviembre }\end{array}$ & $\begin{array}{l}\text { La mayoría de los niños de la } \\
\text { comunidad siguen estudiando }\end{array}$ & $\begin{array}{l}\text { Los jóvenes no continúan } \\
\text { sus estudios superiores, } \\
\text { por falta de recursos } \\
\text { económicos. }\end{array}$ \\
\hline Salud & $\begin{array}{l}\text { No cuenta con un centro } \\
\text { de salud }\end{array}$ & $\begin{array}{l}\text { Alto conocimiento de medicina } \\
\text { ancestral. }\end{array}$ & $\begin{array}{l}\text { No existe un botiquín, ni } \\
\text { conocimientos de } \\
\text { primeros auxilios, para } \\
\text { casos de trauma graves. }\end{array}$ \\
\hline $\begin{array}{l}\text { Acceso y uso de } \\
\text { espacio público }\end{array}$ & $\begin{array}{l}1 \text { cancha cubierta y } 1 \text { un } \\
\text { comedor comunitario. }\end{array}$ & $\begin{array}{l}\text { Existen espacios de } \\
\text { concentración social. }\end{array}$ & \\
\hline $\begin{array}{l}\text { Organización y } \\
\text { tejido social }\end{array}$ & $\begin{array}{l}3 \text { asociaciones de turismo, } \\
\text { artesanal y agrícola. }\end{array}$ & $\begin{array}{c}\text { El compromiso de las personas } \\
\text { por la organización y el } \\
\text { desarrollo de su comunidad. }\end{array}$ & \\
\hline Grupos étnicos & $\begin{array}{l}\text { 95,77\% de la población es } \\
\text { indígena perteneciente a la } \\
\text { nacionalidad Kichwa y el } \\
4,23 \% \text { son mestizos. }\end{array}$ & $\begin{array}{l}\text { La mayoría de la población } \\
\text { quiere recuperar su riqueza } \\
\text { cultural. } \\
\text { Mantienen su idioma nativo. }\end{array}$ & $\begin{array}{l}\text { Erosión cultural por } \\
\text { migración. }\end{array}$ \\
\hline Cohesión social & Comunidad organizada & Trabajo colectivo & \\
\hline Patrimonio cultural & $\begin{array}{l}14 \text { bienes pertenecientes al } \\
\text { patrimonio cultural } \\
\text { intangible }\end{array}$ & $\begin{array}{c}\text { El patrimonio cultural permite } \\
\text { desarrollar el turismo } \\
\text { comunitario, las industrias } \\
\text { culturales y creativas. }\end{array}$ & $\begin{array}{l}\text { Transmisión generacional } \\
\text { fragmentada entre } \\
\text { generaciones. }\end{array}$ \\
\hline $\begin{array}{l}\text { Movimientos } \\
\text { migratorios y } \\
\text { vectores de } \\
\text { movilidad humana. }\end{array}$ & $\begin{array}{l}40 \text { personas, } 39 \text { dentro del } \\
\text { país y uno fuera del país, } \\
\text { causa principal busca de } \\
\text { trabajo }\end{array}$ & $\begin{array}{c}\text { Hay un bajo índice que } \\
\text { migración, existe el recurso } \\
\text { humano para futuras fuentes de } \\
\text { empleo }\end{array}$ & $\begin{array}{l}\text { Capacitaciones para las } \\
\text { diferentes áreas de trabajo }\end{array}$ \\
\hline
\end{tabular}

Fuente: Elaboración propia

\section{c. Económico-productivo}

1. Sistema de producción agrícola

En la comunidad Capirona, Parroquia Puerto Napo la actividad agrícola es principalmente para el auto consumo y una parte para vender. Los productos que usualmente se produce son: el plátano, yuca, maíz y cacao. Y para vender son el plátano y la yuca en el terminal terrestre de Tena.

\section{Sistema de producción pecuaria}

En lo que respecta a la actividad pecuaria en la Comunidad Kichwa Capirona las familias solo crían aves (gallinas) destinadas para su autoconsumo, venta e intercambio con otros productos.

\section{Infraestructura de apoyo a la producción}

No existe apoyo de infraestructura para la crianza de animales tanto de especies mayores y especies menores.

\section{Infraestructura productiva}

No existe apoyo de una infraestructura productiva de ningún tipo. 


\section{Resultado general del subsistema económico - productivo}

Tabla 6. Síntesis del subsistema económico - productivo por variables principales

\begin{tabular}{|c|c|c|c|}
\hline VARIABLES & INDICADOR & POTENCIALIDADES & PROBLEMAS \\
\hline Demografía & $\begin{array}{c}\text { El } 75 \% \text { de personas están } \\
\text { aptas para trabajar }\end{array}$ & $\begin{array}{l}\text { Disponibilidad de mano de } \\
\text { obra local }\end{array}$ & \\
\hline Educación & $\begin{array}{l}\text { De los niños que terminan la } \\
\text { escuela, solo el } 2 \% \text { de } \\
\text { jóvenes acceden al bachiller }\end{array}$ & $\begin{array}{c}\text { Existe } 2 \text { CECIB } \\
\text { Niños y jóvenes les } \\
\text { gustaría seguir estudiando }\end{array}$ & $\begin{array}{l}\text { Accesibilidad } \\
\text { Falta del recurso } \\
\text { económico }\end{array}$ \\
\hline Salud & $\begin{array}{c}\text { Problemas respiratorios y } \\
\text { estomacales }\end{array}$ & $\begin{array}{c}\text { Conocimiento en medicina } \\
\text { ancestral }\end{array}$ & $\begin{array}{l}\text { No existe centro de } \\
\text { salud en la comunidad }\end{array}$ \\
\hline Trabajo y empleo & $\begin{array}{l}\text { El } 90 \% \text { de la población tiene } \\
\text { ingresos inferiores al sueldo } \\
\text { básico y son agricultores }\end{array}$ & $\begin{array}{l}\text { Los productos agrícolas } \\
\text { son comercializados }\end{array}$ & $\begin{array}{c}\text { Falta de fuentes de } \\
\text { trabajo } \\
\text { Precios bajos en sus } \\
\text { productos }\end{array}$ \\
\hline \multicolumn{4}{|l|}{ Estructura productiva } \\
\hline $\begin{array}{c}\text { Relación entre sectores } \\
\text { económicos }\end{array}$ & $\begin{array}{l}\text { La agricultura se encuentra } \\
\text { en el sector primario de } \\
\text { producción }\end{array}$ & & $\begin{array}{l}\text { Falta de asesoría } \\
\text { técnica para la } \\
\text { elaboración de } \\
\text { productos procesados }\end{array}$ \\
\hline $\begin{array}{c}\text { Principales actividades } \\
\text { económicas }\end{array}$ & Agricultura & $\begin{array}{l}\text { Buena calidad de los } \\
\text { productos } \\
\text { Fuente principal de } \\
\text { ingresos económicos }\end{array}$ & $\begin{array}{l}\text { Bajos precios para la } \\
\text { comercialización de } \\
\text { excedentes }\end{array}$ \\
\hline Principales productos & Plátano, yuca, maíz & $\begin{array}{l}\text { Disponibilidad de } \\
\text { alimentos } 100 \% \text { orgánicos }\end{array}$ & $\begin{array}{l}\text { Falta de conocimientos } \\
\text { en producción agrícola }\end{array}$ \\
\hline $\begin{array}{c}\text { Establecimientos } \\
\text { económico-productivos }\end{array}$ & Ninguno & & \\
\hline Factores productivos & $\begin{array}{l}\text { Productos de cultivo } \\
\text { trimestral y semestral }\end{array}$ & Productos orgánicos & $\begin{array}{l}\text { Periodos extensos en la } \\
\text { cosecha y bajos precios }\end{array}$ \\
\hline \multicolumn{4}{|l|}{ Modos de producción } \\
\hline $\begin{array}{l}\text { Seguridad y soberanía } \\
\text { alimentaria }\end{array}$ & $\begin{array}{l}\text { las familias poseen fincas } \\
\text { que son destinadas para los } \\
\text { sembríos }\end{array}$ & $\begin{array}{l}\text { Estatutos definidos por la } \\
\text { comunidad }\end{array}$ & $\begin{array}{c}\text { Alteración del entorno } \\
\text { natural }\end{array}$ \\
\hline $\begin{array}{c}\text { Infraestructura de apoyo } \\
\text { a la producción }\end{array}$ & $\begin{array}{l}\text { Inexistencia de } \\
\text { infraestructuras }\end{array}$ & & \\
\hline
\end{tabular}

Fuente: Elaboración propia

\section{d. Asentamientos humanos}

\section{Disponibilidad de servicios básicos y de vivienda}

En la Comunidad Kichwa Capirona el 100\% de los pobladores no cuenta con servicios básicos completos, ya que solo se cuenta con el servicio de energía eléctrica. Sin embargo, el $21 \%$ de familias ni siquiera cuenta con servicio eléctrico. El $69.01 \%$ de los

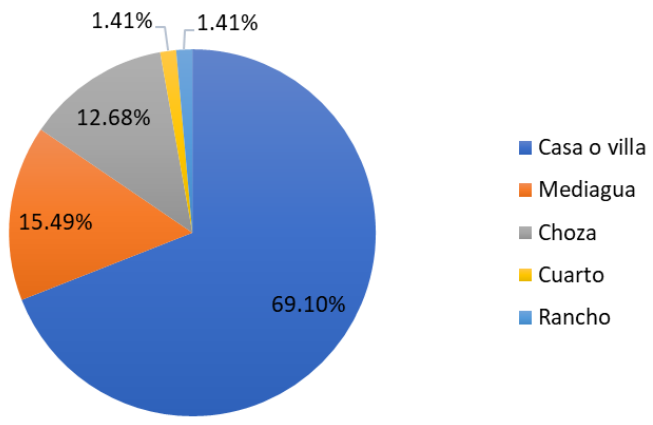

Figura 7. Tipo de vivienda Fuente: Elaboración propia 
pobladores cuenta con viviendas del Proyecto MIDUVI 2010, el $15.49 \%$ poseen mediaguas, el $12.68 \%$ viven en chozas, $1.41 \%$ en ranchos y el $1.41 \%$ restante en cuartos (Figura 7).

\section{Disponibilidad y características del servicio de agua de consumo humano y uso doméstico}

Las familias de la comunidad Capirona no reciben agua potable, ni agua por tubería, por lo que obtienen el agua para consumo y uso doméstico de: $78.87 \%$ del Río Puní, $14.08 \%$ agua lluvia y $7.04 \$$ por bombas de agua (Figura 8).

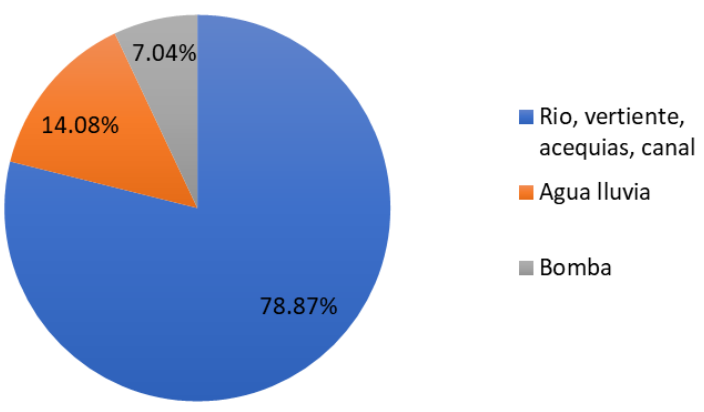

Figura 8. Fuente del agua de consumo de la comunidad Fuente: Elaboración propia

\section{Disponibilidad y caracterización del servicio de saneamiento básico}

En lo que respecta al servicio de saneamiento básico se obtuvo lo siguiente: el $53.52 \%$ ninguno (aire libre), $29.58 \%$ pozo ciego, el $14.08 \%$ pozo séptico y el 2.82 escusado exclusivo para el hogar (Figura 9).

\section{Manejo de desechos sólidos}

La comunidad no cuenta con ningún servicio de recolección de desechos sólidos y estos son manejados de la siguiente manera: $53.53 \%$ incineración, $38.03 \%$ entierran, $4.23 \%$ en terreno baldío y el $1.41 \%$ llevan al cantón Tena (Figura 10).

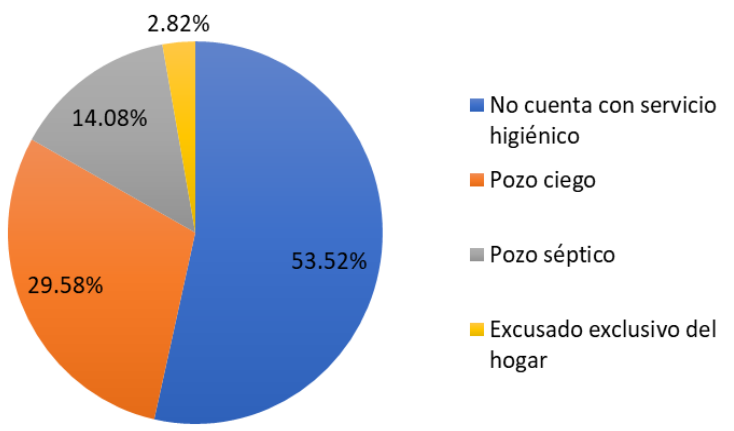

Figura 9. Tipo de servicio higiénico Fuente: Elaboración propia

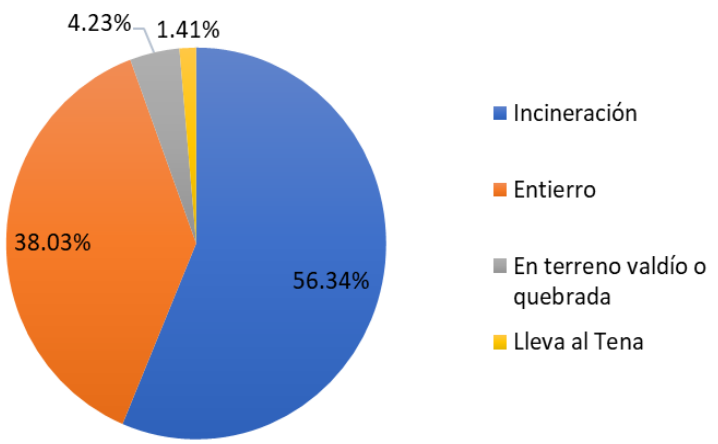

Figura 10. Eliminación de la basura Fuente: Elaboración propia 


\section{Tratamiento de residuos}

El $58.57 \%$ si realiza un tratamiento a los residuos y el $41.43 \%$ no, del $58.57 \%$ un $85.37 \%$ utiliza los residuos como abono orgánico y el restante lo recicla (Figura 11).

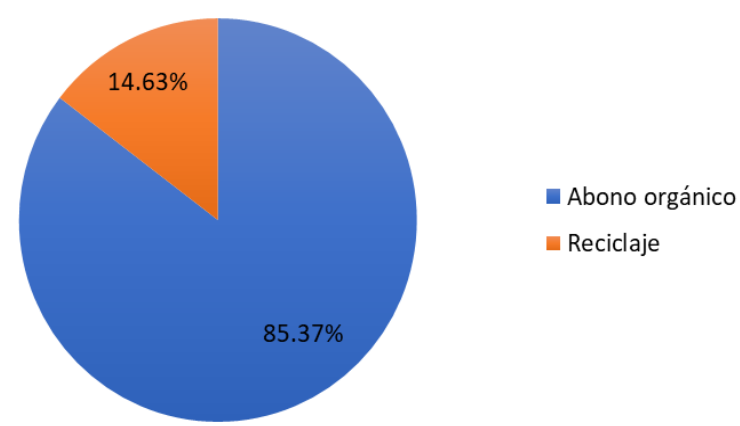

Figura 11. Tipo de tratamiento de los residuos

Fuente: Elaboración propia

\section{Disponibilidad de servicios de electricidad}

En la comunidad Capirona, el 78,87\% de las familias poseen energía eléctrica, mientras que el restante $21,13 \%$ no tiene acceso a este servicio (Figura 12).

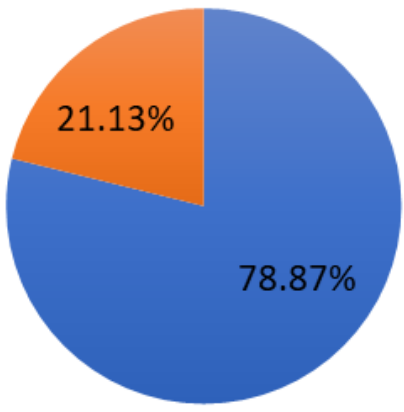

Cuenta con servicio eléctrico

No cuenta con servicio eléctrico

Figura 12. La vivienda cuenta con electricidad Fuente: Elaboración propia

\section{Servicios de educación disponibles}

Existen dos Centros Educativos Comunitarios Intercultural Bilingüe, estos son: CECIB Capirona y CECIB 3 de noviembre, pero estos centros ofrecen educación solo hasta el séptimo de básica.

\section{Centro de desarrollo infantil}

Los dos centros educativos anteriores: CECIB Capirona y CECIB 3 de noviembre, están a disposición para los más pequeños de la Comunidad Capirona.

\section{Servicio de salud}

No existe ningún centro de salud en la comunidad, los habitantes se trasladan al centro de salud más cercano.

\section{Necesidades básicas insatisfechas}

En general la comunidad Capirona presenta limitaciones en cuanto a los servicios básicos, servicios de salud y servicios de educación; ya que el centro de salud más cercano es el "Centro de salud Atahualpa" ubicado a 30min de la comunidad.

\section{Resultado general del subsistema asentamientos humanos}

La Tabla 7 presenta la síntesis del análisis del subsistema de asentamientos humanos. Entre los problemas más importantes es la falta de acceso a servicios básicos por parte de los pobladores de la comunidad, así como la falta de proyectos en beneficio de este sector. Si embargo, la fortaleza de la comunidad se centra en su fuerte cohesión social. 
Tabla 7. Síntesis del subsistema asentamientos humanos por variables principales

\begin{tabular}{|c|c|c|c|}
\hline VARIABLES & INDICADOR & POTENCIALIDADES & PROBLEMAS \\
\hline $\begin{array}{l}\text { Red nacional de } \\
\text { asentamientos humanos }\end{array}$ & $\begin{array}{l}\text { La comunidad de Capirona se } \\
\text { encuentra dividida en dos por } \\
\text { el cruce del río Puní }\end{array}$ & $\begin{array}{l}\text { Posee una buena } \\
\text { organización interna, } \\
\text { existe designaciones de } \\
\text { actividades }\end{array}$ & \\
\hline $\begin{array}{l}\text { Infraestructura y acceso } \\
\text { a servicios básicos }\end{array}$ & $\begin{array}{l}\text { Inexistencia de servicios } \\
\text { básicos, el } 75 \% \text { familias } \\
\text { disponen de energía eléctrica }\end{array}$ & $\begin{array}{l}\text { Armonía con el medio } \\
\text { ambiente }\end{array}$ & $\begin{array}{l}\text { Falta de comunicación, } \\
\text { enfermedades }\end{array}$ \\
\hline $\begin{array}{l}\text { Acceso a servicios de } \\
\text { educación y salud }\end{array}$ & $\begin{array}{l}\text { Todos los niños y niñas } \\
\text { estudian, inexistencia de un } \\
\text { centro de salud }\end{array}$ & $\begin{array}{l}\text { Conocimientos de } \\
\text { plantas medicinales }\end{array}$ & $\begin{array}{l}\text { Los niños no pueden } \\
\text { seguir estudiando por } \\
\text { falta de dinero }\end{array}$ \\
\hline Acceso a vivienda & $\begin{array}{l}\text { El } 70 \% \text { de las familias poseen } \\
\text { casa propia }\end{array}$ & & $\begin{array}{l}\text { Viviendas sin } \\
\text { infraestructura } \\
\text { adecuada }\end{array}$ \\
\hline $\begin{array}{l}\text { Localización de } \\
\text { asentamientos humanos }\end{array}$ & $\begin{array}{l}\text { Las viviendas están } \\
\text { localizadas al borde de las } \\
\text { carreteras }\end{array}$ & & \\
\hline $\begin{array}{l}\text { Dispersión y } \\
\text { concentración } \\
\text { poblacional }\end{array}$ & $\begin{array}{l}\text { El } 80 \% \text { de pobladores viven } \\
\text { en la comunidad }\end{array}$ & $\begin{array}{l}\text { Existe un fuerte lazo de } \\
\text { compañerismo }\end{array}$ & $\begin{array}{l}\text { Migración de la } \\
\text { población por aspectos } \\
\text { económicos y } \\
\text { educativos }\end{array}$ \\
\hline $\begin{array}{l}\text { Caracterización de } \\
\text { amenazas y capacidad } \\
\text { de respuesta }\end{array}$ & $\begin{array}{l}\text { No existen planes en caso de } \\
\text { emergencias }\end{array}$ & & \\
\hline $\begin{array}{l}\text { Proyectos estratégicos } \\
\text { Nacionales }\end{array}$ & No existen proyectos & & \\
\hline
\end{tabular}

Fuente: Elaboración propia

\section{e. Movilidad, energía y conectividad}

\section{Servicios de transporte}

El servicio de transporte que llega a la Comunidad de Capirona es de la Cooperativa Centinela del Tena con los siguientes horarios: 6:00am, 11:14am y 3:00pm, estos salen del Terminal Terrestre del Tena, con un valor de $\$ 1,50$.

\section{Acceso a medios de comunicación}

No existe accesibilidad a medios de comunicación debido a la localización de la comunidad.

\section{Caracterización de la red vial rural}

La accesibilidad hacia la comunidad Capirona es la siguiente: desde la parroquia Puerto Napo la vía es de primer orden y de buen estado $(13 \mathrm{~km})$ y los $15 \mathrm{~km}$ siguientes la vía es de segundo orden, es lastrada y su estado es regular.

\section{Resultado general del subsistema movilidad, energía y conectividad}

En la Tabla 8 se aprecia el resumen del análisis correspondiente al subsistema de movilidad, energía y conectividad. En la comunidad no existe el servicio de telecomunicaciones, lo cual presenta problemas para el normal desenvolvimiento de muchas de sus actividades, pero en especial en casos de emergencia. También se detectó que no todas las viviendas poseen servicio eléctrico. 
Tabla 8. Síntesis del subsistema movilidad, energía y conectividad por variables principales

\begin{tabular}{|c|c|c|c|}
\hline VARIABLES & INDICADOR & POTENCIALIDADES & PROBLEMAS \\
\hline $\begin{array}{l}\text { Acceso a servicios de } \\
\text { telecomunicaciones }\end{array}$ & $\begin{array}{l}\text { Inexistencia del servicio de } \\
\text { telecomunicación }\end{array}$ & & $\begin{array}{l}\text { Dificultades en la } \\
\text { comunicación en el caso } \\
\text { de alguna emergencia }\end{array}$ \\
\hline $\begin{array}{l}\text { Tipo de generación } \\
\text { de energía eléctrica }\end{array}$ & $\begin{array}{l}\text { Servicio de la empresa eléctrica } \\
\text { pero no todas las viviendas } \\
\text { poseen del servicio eléctrico }\end{array}$ & & \\
\hline $\begin{array}{l}\text { Redes viales y de } \\
\text { transporte }\end{array}$ & $\begin{array}{l}\text { El estado de la vía de acceso a } \\
\text { la comunidad es lastrado y está } \\
\text { en buen estado }\end{array}$ & $\begin{array}{l}\text { Permite el fácil acceso } \\
\text { en vehículo }\end{array}$ & \\
\hline
\end{tabular}

Fuente: Elaboración propia

\section{f. Político-institucional y participación ciudadana}

La toma de decisiones en la comunidad se realiza mediante asambleas que son presididas por la presidenta ayudada de la secretaria que toma nota, en donde existe una participación inclusiva de todos los pobladores de la comunidad. Y posterior a ello la presidenta realiza los trámites pertinentes en vinculación a otros niveles de gobierno.

\section{Mapeo de actores públicos, privados, comunitarios que intervienen en el territorio}

Tabla 9. Actores que intervienen en la comunidad

\begin{tabular}{|c|c|c|c|c|}
\hline ACTORES & $\begin{array}{c}\text { COMPETENCIAS /FUNCIONES/ } \\
\text { ACTIVIDADES }\end{array}$ & INTERÉS & POTENCIALIDADES & LIMITACIONES \\
\hline $\begin{array}{l}\text { Instituto } \\
\text { Nacional de } \\
\text { Patrimonio } \\
\text { Cultural R2 }\end{array}$ & $\begin{array}{l}\text { "Investigar, conservar, preservar, } \\
\text { restaurar, exhibir y promocionar el } \\
\text { Patrimonio Cultural en el Ecuador; } \\
\text { así como regular de acuerdo con la } \\
\text { Ley todas las actividades de esta } \\
\text { naturaleza que se realicen en el país". }\end{array}$ & $\begin{array}{l}\text { Salvaguardar } \\
\text { el patrimonio } \\
\text { cultural } \\
\text { material e } \\
\text { inmaterial. }\end{array}$ & $\begin{array}{l}\text { Profesionales } \\
\text { capacitados. } \\
\text { Asistencia técnica } \\
\text { Desarrollo de nuevas } \\
\text { metodologías para la } \\
\text { gestión patrimonial. }\end{array}$ & $\begin{array}{l}\text { Recursos } \\
\text { económicos }\end{array}$ \\
\hline
\end{tabular}

Fuente: Elaboración propia

\section{Valoración del ejercicio de poder y legitimidad de los actores sobre el territorio \\ a. Análisis de redes de los actores sociales}

La Figura 13 presenta la red de relaciones que se dan entre diferentes actores dentro del territorio, ya sean estos individuos, grupos u organizaciones). Se ha seleccionado 5 instancias públicas en el territorio tanto a nivel parroquial, cantonal, provincial y nacional, porque adquieren competencias o responsabilidades compartidas en la gestión cultural, exclusivamente el GAD Municipal del Tena en el ámbito del patrimonio cultural inmaterial, organismo que debe trabajar de forma articulada con otras instituciones para garantizar la salvaguardia de las expresiones culturales de la comunidad, actividades que deben ser gestionadas desde el departamento de cultura de la institución municipal. En el tejido asociativo se enlistó toda forma de organización a través de cual los pobladores optimizan tareas, recursos, y tiempo, alcanzando un mejor resultado en cada actividad. Finalmente, en la base social se encuentran todos los integrantes de la localidad, desde 
niños/as, jóvenes, hombres adultos, mujeres adultas y abuelos/as, principales actores del quehacer cultural, siendo la razón para la formulación y ejecución del plan de salvaguardia.

Figura 13. Selección de agentes sociales en el territorio

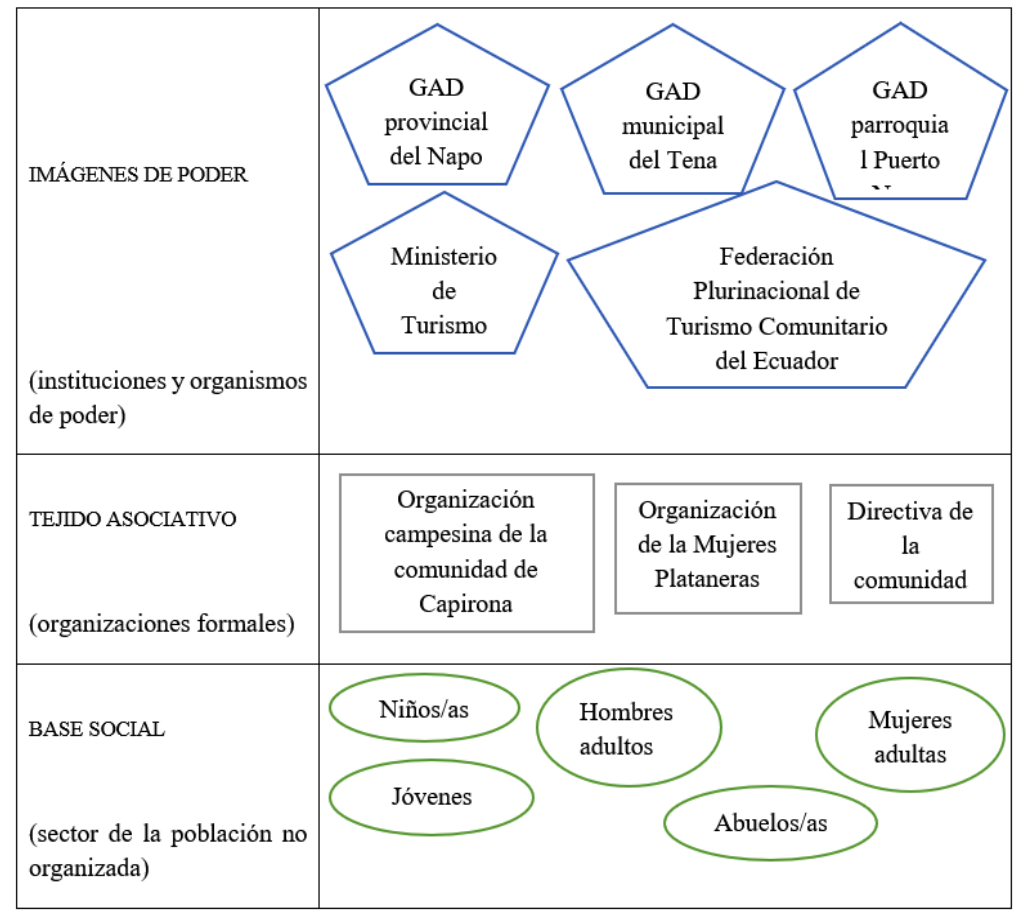

Fuente: Elaboración propia

\section{b. Tipos de relación entre los diferentes actores del territorio}

La Figura 14 muestra los tipos de relaciones a nivel de personas, grupos e instituciones el tipo de relación más recurrente es de colaboración, debido al grado de apoyo e interés que muestran hacia las acciones de salvaguardia del patrimonio cultural inmaterial, siendo factible un trabajo mancomunado entre los diferentes sectores sociales.

También existen relaciones de dependencia por parte de la directiva de la comunidad con el GAD Municipal de Tena y el GAD Provincial de Napo porque son instituciones que posiblemente pueden financiar los proyectos del plan de salvaguardia. Otra forma de relación es de aislamiento de jóvenes y niños/as con la directiva de la comunidad, a causa de opiniones divididas en cuanto a conservar o no las expresiones culturales en un mundo cada vez globalizado. De igual manera, se visualiza una relación de interés por parte del GAD Parroquial de Puerto Napo con la comunidad, además de ser la entidad más cercana a la zona de estudio, la cual se ha preocupado por plantear acciones contundentes que aporten a la salvaguardia de la riqueza cultural de la comunidad. Y, por último, existen relaciones puntuales entre la directiva de la comunidad y el grupo de mujeres plataneras y la organización campesina, donde tratan asuntos afines a sus áreas 
de trabajo, pero de igual manera se puede contar con el apoyo de estos dos grupos durante el proceso de implementación sobre proyectos de Turismo Comunitario.

Finalmente, se reconoce a la directiva de la comunidad como el actor responsable de la gestión e implementación del plan, por su nivel de influencia, poder de decisión y relación con otros sectores sociales.

Figura 14. Tipos de relación entre los diferentes actores del territorio

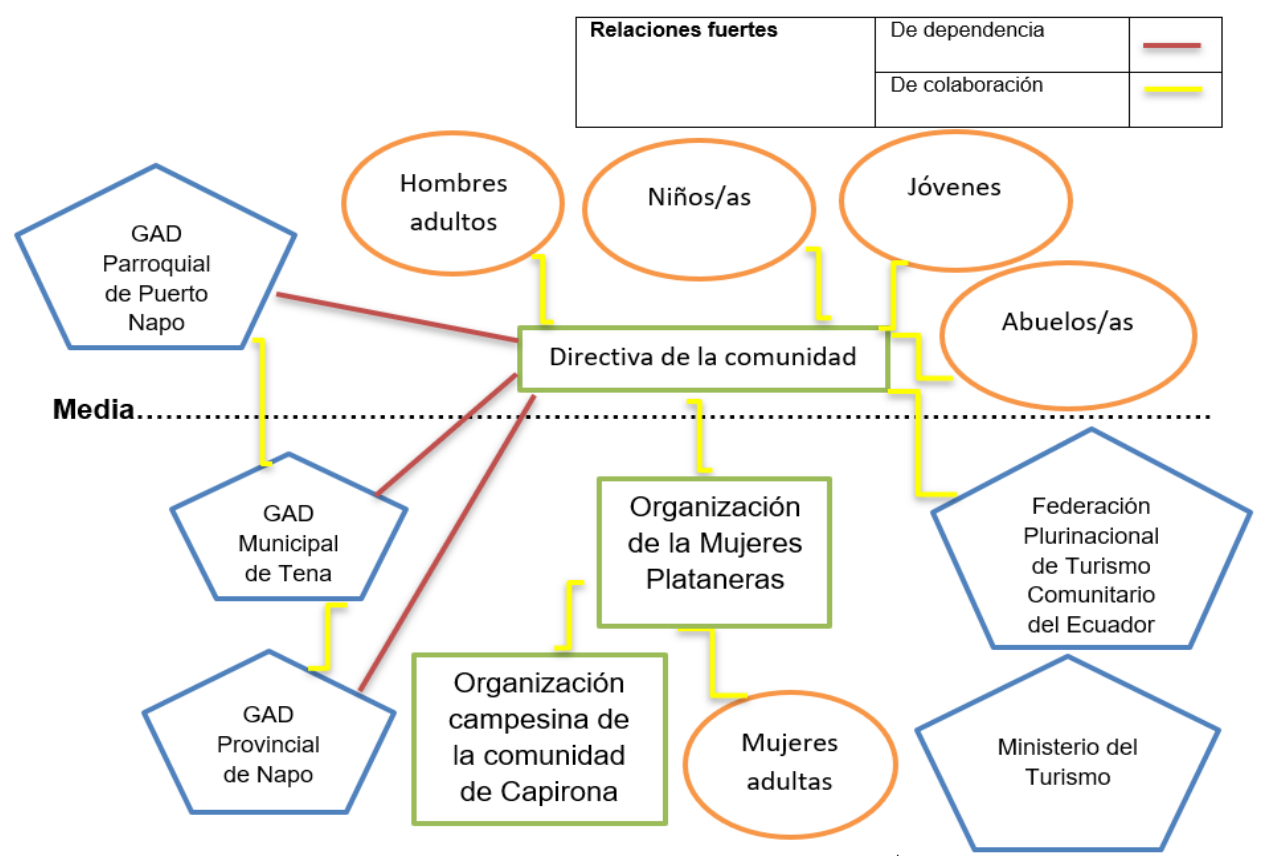

Fuente: Elaboración propia

\section{Conjuntos de acción}

Se ha consolidado tres conjuntos de acción, dos a nivel de organizaciones y uno a nivel institucional, producto de una buena relación, confianza y comunicación que mantienen estos grupos entre sí. Los actores son protagonistas durante la ejecución del plan de acción. Así, la comunidad como principal interesada en la protección de sus expresiones culturales, por medio del Turismo Comunitario, gestiona e implementa el plan de salvaguardia a través de la directiva y los grupos específicos de trabajo, como el grupo jóvenes que constituirá un pilar estratégico para que la juventud se involucre en las actividades culturales formuladas en el plan y a mejorar la relación con la directiva de la comunidad. También, el GAD Municipal de Tena será participe del proceso de salvaguardia, con base a su competencia en la gestión del patrimonio cultural inmaterial, delegado funciones y realizando alianzas con otros sectores sociales vinculados a la gestión cultural, obteniendo cualquier tipo de contribución que favorezca a la implementación del plan de salvaguardia, logrando así que todas y todos participen de este proceso comunitario, con 
ISSN: 2602-8085

el único afán de aportar a la protección y continuidad de los elementos patrimoniales de la localidad de una generación a otra (Figura 15).

Figura 15. Conjuntos de acción para la ejecución del proyecto de Turismo Comunitario de la Comunidad Kichwa Capirona.

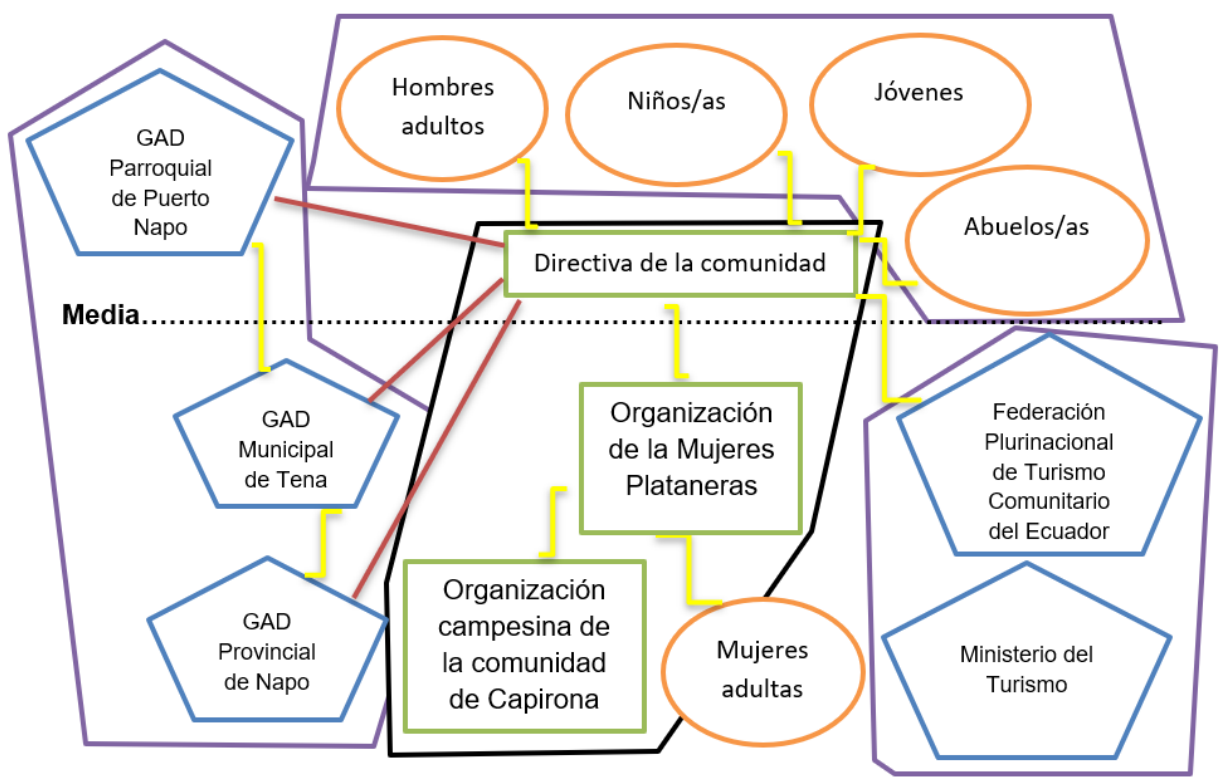

Fuente: Elaboración propia

\section{Resultado general del subsistema político institucional y participación ciudadana}

En cuanto a lo referente al subsistema político institucional y la participación ciudadana, se detectaron algunos problemas cuyas soluciones deben ser trabajadas a nivel interno con la asistencia del GAD parroquial. La síntesis de este análisis se presenta en la tabla 10.

Tabla 10. Síntesis del subsistema político institucional y participación por variables principales

\begin{tabular}{|c|c|c|c|}
\hline Variables & Indicador & Potencialidades & Problemas \\
\hline $\begin{array}{l}\text { Instrumentos de planificación } \\
\text { y ordenamiento territorial }\end{array}$ & $\begin{array}{l}\text { No existe información } \\
\text { sobre la comunidad en los } \\
\text { PDOTs de la zona }\end{array}$ & & $\begin{array}{l}\text { No se cuenta con la } \\
\text { información base para } \\
\text { iniciar proyectos }\end{array}$ \\
\hline \multicolumn{4}{|l|}{$\begin{array}{l}\text { Mapeo de actores públicos, } \\
\text { privados, sociedad civil }\end{array}$} \\
\hline $\begin{array}{l}\text { Estructura y capacidades } \\
\text { comunitarias }\end{array}$ & $\begin{array}{l}\text { Existe un presidente que } \\
\text { representa a la comunidad }\end{array}$ & $\begin{array}{l}\text { Tiene una buena } \\
\text { organización interna }\end{array}$ & Falta de comisiones \\
\hline
\end{tabular}

Fuente: Elaboración propia

\section{Conclusiones.}

- El Diagnóstico situacional de la comunidad Capirona, permitió conocer las necesidades, potencialidades y precarias condiciones en que viven sus pobladores, esto debido 
principalmente a la inexistencia de servicios básicos tales como; agua potable, sistema de alcantarillado, recolección de residuos sólidos y un servicio de electricidad que no llega a la totalidad de las viviendas de sus habitantes. Entre otros problemas que la comunidad enfrenta es el mal estado de las vías de acceso, desempleo, migración, destrucción de bosques por la tala de árboles y cacería furtiva. La desatención por parte de las autoridades ha contribuido al estancamiento económico, social y ambiental del sector, por tal razón la forma principal de subsistencia es la agricultura para consumo interno en un $80 \%$ y un $20 \%$ para comercialización.

- Por lo antes expuesto, se recomienda la intervención en el territorio con el fin de presentar a los habitantes de la comunidad Capirona la oportunidad de desarrollar actividades productivas sostenibles, como es el caso del turismo, el cual, bien manejado, contribuirá a la mejora de las condiciones de vida de sus pobladores. En el caso particular del Turismo, la comunidad presenta recursos naturales y culturales importantes que se deben proteger, potenciar y aprovechar de forma sostenible.

- Además de las actividades productivas, las autoridades deberían trabajar, en conjunto con la gente de la comunidad, en la búsqueda de alternativas para la dotación de servicios básicos, los cuales, además de ser esenciales para la vida, son derechos humanos.

\section{Referencias Bibliográficas}

Gobierno Parroquial Rural de Puerto Napo. (2011). Plan de desarrollo y ordenamiento territorial $2011-2015$.

Gobierno Parroquial Rural de Puerto Napo. (2015). Plan de desarrollo y ordenamiento territorial 2015 - 2019. Retrieved from http://app.sni.gob.ec/snilink/sni/PORTAL_SNI/data_sigad_plus/sigadplusdocumentofinal/1560602910001_DPO T\%20Pto\%20Napo_v8\%20impresion_29-10-2015_16-55-33.pdf

Gobierno Parroquial Rural de Puerto Napo. (2015). Plan de desarrollo y ordenamiento territorial 2015 - 2019. Retrieved from http://app.sni.gob.ec/snilink/sni/PORTAL_SNI/data_sigad_plus/sigadplusdocumentofinal/1560602910001_DPO T\%20Pto\%20Napo_v8\%20impresion_29-10-2015_16-55-33.pdf

Gobierno Autónomo Descentralizado Municipal de Tena. (2014). Actualización plan de desarrollo y ordenamiento territorial; diagnóstico. Retrieved from https://www.tena.gob.ec/index.php/tena/plan-de-desarrollo\#

Gobierno Parroquial Rural de Puerto Napo. (2011). Plan de desarrollo y ordenamiento territorial 2011 - 2015. Retrieved from

Hernandez, D. E. (2015). Diagnóstico Situacional. In Estrategia Empresarial.

Higgins-Desbiolles, F. (2018). Sustainable tourism: Sustaining tourism or something more? Tourism Management Perspectives, 25, 157-160. doi:https://doi.org/10.1016/j.tmp.2017.11.017

Instituto Geográfico Militar. (2020). Carta topográfica Puerto Napo. Retrieved from http://www.igm.gob.ec/work/files/cartabase_ori/o/OIV_A1.htm 
Linares, H. L., \& Garrido, G. M. (2014). Del desarrollo turístico sostenible al desarrollo local. Su comportamiento complejo. PASOS Revista de Turismo y Patrimonio Cultural, 12(2), 453466.

Ministerio del Ambiente. (2020). Sistema Nacional de Áreas Protegidas del Ecuador; Turismo Sostenible. Retrieved from http://areasprotegidas.ambiente.gob.ec/es/content/turismosostenible

Organización Mundial del Turismo. (2019). Panorama del Turismo Internacional. Retrieved from https://www.e-unwto.org/doi/pdf/10.18111/9789284421237

Organización Mundial del Turismo. (2020). Glosario de términos de turismo. Retrieved from https://www.unwto.org/es/glosario-terminos-turisticos

Pineda Nariño, J., \& Arias Guarín, Y. T. (2014). Análisis situacional de la comunidad Las Colonias y diseño de un instrumento de planificación social. Universidad Libre Seccional Pereira, Retrieved

from http://repositorio.unilibrepereira.edu.co:8080/pereira/bitstream/handle/123456789/249/A N707F 1.PDF?sequence $=1$

Secretaría Nacional de Planificación y Desarrollo. (2015). Proceso para la elaboración de planes de desarrollo $y$ ordenamiento territorial. Retrieved from https://www.planificacion.gob.ec/metodologias/

World Travel and Tourism Council. (2020). Travel and tourism global economic impact and trends 2020. 


\section{PARA CITAR EL ARTÍCULO INDEXADO.}

Salazar Mora, S. L., Tierra Tierra, N. P., \& Salas Castelo, E. M. (2020). Diagnóstico situacional de la comunidad Capirona, parroquia Puerto Napo, cantón Tena, provincia de Napo, previo a la elaboración del inventario de atractivos turísticos. Ciencia Digital, 4(3), 355-377. https://doi.org/10.33262/cienciadigital.v4i3.1360

\section{\Ciencia}

El artículo que se publica es de exclusiva responsabilidad de los autores y no necesariamente reflejan el pensamiento de la Revista Ciencia Digital.

El artículo queda en propiedad de la revista y, por tanto, su publicación parcial y/o total en otro medio tiene que ser autorizado por el director de la Revista Ciencia Digital.
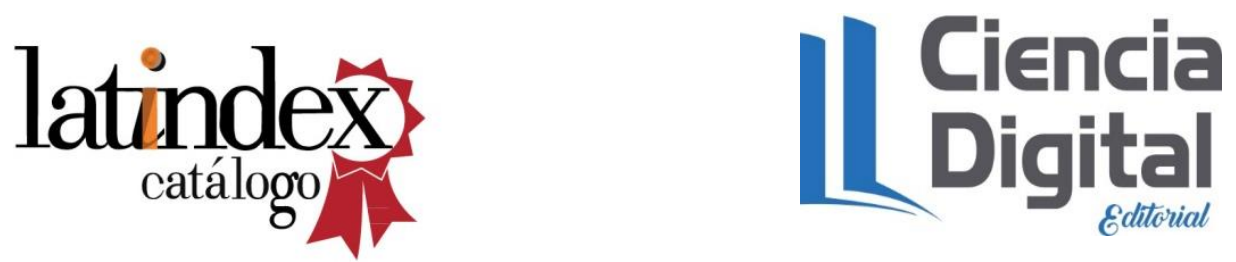